\title{
The Coastal Jet: Observations of Surface CURRENTS OVER THE OREGON CONTINENTAL SHELF From HF RADAR
}

By P. Michael Kosro, John A. Barth

and P. Ted Strub

$\mathrm{T}$ HE OCEAN CIRCULATION over the Oregon shelf during spring and summer is dominated by the effects of coastal upwelling. Equatorward winds drive an offshore Ekman transport in the surface layer, which produces divergent flow at the coast and the upwelling of deeper, colder, nutrient-enhanced waters (Huyer, 1990). At the surface, the boundary between the upwelled and oceanic waters is often a front, and the upwelling-induced horizontal density gradients support an equatorward coastal jet (Mooers et al., 1976). The annual onset of persistent upwelling conditions often occurs abruptly in an event called the spring transition (Huyer, et al., 1979; Strub, et al., 1987), which is characterized by a persistent drop in coastal sea level and a tendency to persistence of equatorward wind forcing (punctuated by occasional wind reversals). Although fluctuations in the alongshore current have been shown to be coherent over large alongshore scales (Huyer et al., 1975), the local spatial variations in the currents are not well known, mainly due to our past inability to map the current field at high resolution in both space and time.

\section{Radar and Conventional Measurements}

The Ocean Surface Current Radar (OSCR), manufactured by GEC Marconi, is a phased-array HF radar system designed for mapping of surface currents in the coastal ocean. During 11-17 May 1995 an OSCR, broadcasting at $25.4 \mathrm{MHz}$, was operated from sites near Bandon, Oregon $\left(43.22^{\circ} \mathrm{N}, 124.39^{\circ} \mathrm{W}\right.$ and $43.12^{\circ} \mathrm{N}, 124.43^{\circ} \mathrm{W}$; see Fig. 1). Site selection (balancing the needs for security, access, ocean coverage, proximity to the water, land-owner permissions, and sufficient free space to set up the $\sim 100$-m-long OSCR receive antennas) resulted in sites separated by only 12

P. Michael Kosro, John A. Barth and P. Ted Strub, College of Oceanic \& Atmospheric Sciences, Oregon State University, 104 Ocean Admin. Bldg., Corvallis, OR 97331-5503, USA. $\mathrm{km}$. This separation limited the resulting range to 25-35 km (depending on screening criteria), and the geometrical accuracy at longer range. Nevertheless, the radar typically measured radial data to the edge of the continental shelf. The percentage of data return was nearly uniform with azimuth angle, although some very near coast cells showed low rates of valid returns. In support of the radar verification, a $307-\mathrm{kHz}$ narrow-band Acoustic Doppler Current Profiler (ADCP) was moored looking upward from a near-bottom float in $\sim 90 \mathrm{~m}$ of water $\left(43.16^{\circ} \mathrm{N}, 124.56^{\circ} \mathrm{W}\right.$, Fig. 1) on 15 May from the fishing vessel Gemini. During 17-19 May, an in situ high-resolution survey was conducted in the region from $R / V$ Wecoma, using CTDs mounted in SeaSoar, a towed, undulating vehicle (Barth and Smith, 1997). Both activities were originally scheduled to fully overlap with

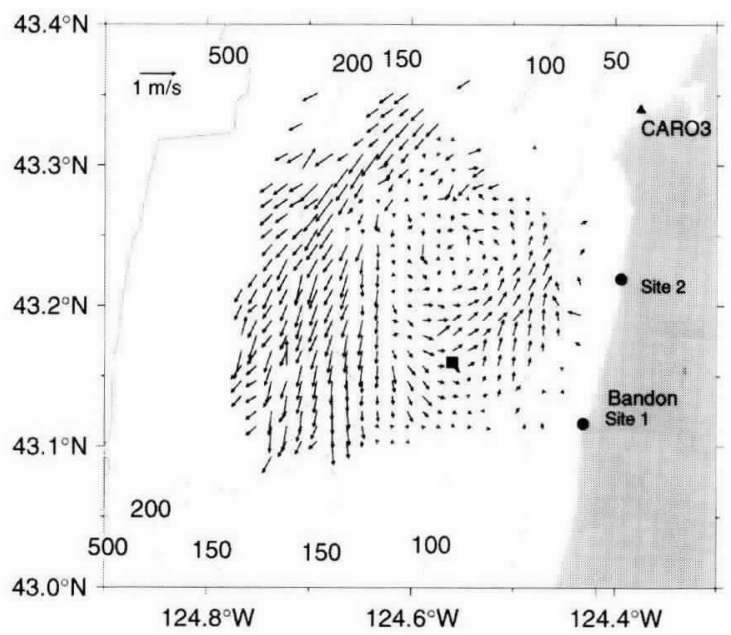

Fig. 1: Example of OSCR map of surface currents at experimental site near Bandon, Oregon, from 12 May 1995, at 10:20 UT. Locations of the two radar sites (circles), of the upward-looking ADCP (square) and of the CMAN wind station (CARO3, triangle) are marked. Depth contours are in meters.
. . . the radar typically

measured radial data to the edge of the continental shelf. 

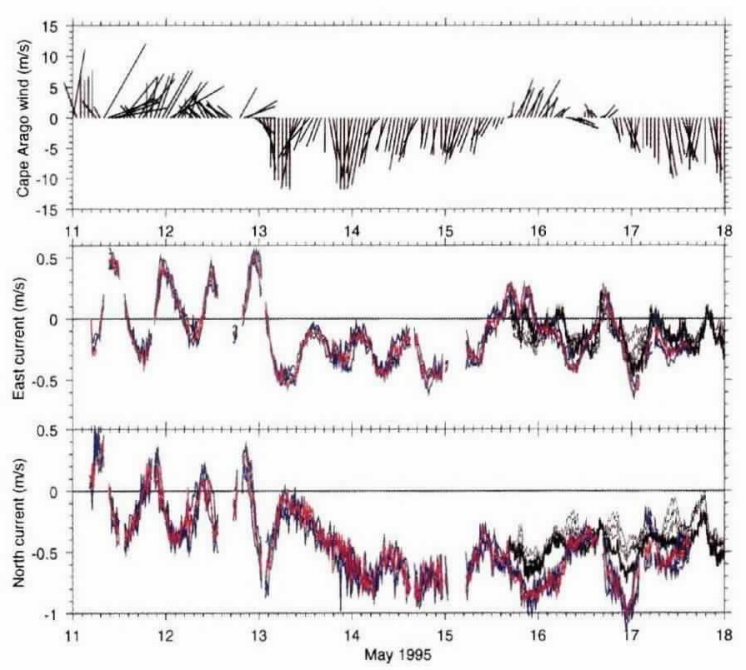

Fig. 2: (A) Hourly winds at Cape Arago C-MAN station (CARO3, Fig. 1) during 11-18 May 1995. (B) Eastward current measured by the ADCP at 7-m subsurface depth (darkest black line), $11 \mathrm{~m}, 14 \mathrm{~m}$, and 18 $m$ (lighter black lines), and by radar at the surface in cells nearest to the ADCP (red line) and at four adjacent cells (blue lines). (C) Same for northward current.

the radar deployment, but last-minute delays in the ship's schedule shortened overlap considerably.

currents near the

mooring position

were dominated by

oscillations of the

semidiurnal tide. . . of $\mathrm{O}(0.4 \mathrm{~m} / \mathrm{s})$ in each component and with the velocity vector rotating clockwise with time.

On 13 May, the winds turned upwelling favorable. The ocean response was like a spring transition-within half a day, the alongshore radar currents at the mooring site, initially weak in the mean, began to accelerate linearly with time to the south, eventually achieving speeds of $\mathrm{O}\left(0.7 \mathrm{~m} \mathrm{~s}^{-1}\right)$, consistent with the spin-up of the equatorward coastal jet.

During their brief overlap (Fig. 2), the highest correlations between the OSCR and the ADCP were found for ADCP velocities at $7 \mathrm{~m}$ (the shallowest uncontaminated measurements) and radar velocities at cells close to, but not exactly at, the one expected to lie over the mooring, probably due to uncertainties in the radar geometry caused by variations in the antennas and in propagation characteristics. Radial ADCP and radar currents showed correlations of 0.84 and 0.78 , and rootmean-square (rms) differences of 12.6 and 16.2 $\mathrm{cm} \mathrm{s}^{-1}$, respectively, for radial currents directed toward sites 1 and 2 . Some of the differences can be explained by extending the vertical shear in the shallowest ADCP measurements to the surface (e.g., period around 0000 UT on 17 May); however, at other times, the ADCP does not observe a shear below 7-m depth, which is sufficient to explain the difference in the two measurements (e.g., 0600 UT on 16 May).

\section{Near-Surface Maps}

Does the southward acceleration observed on the 13-14 May correspond to the spin-up of the coastal jet and the onset of upwelling? The record from satellite Advanced High Resolution Radiomemooring position (Fig. 2) were dominated by os-
cillations of the semidiurnal tide, with amplitude
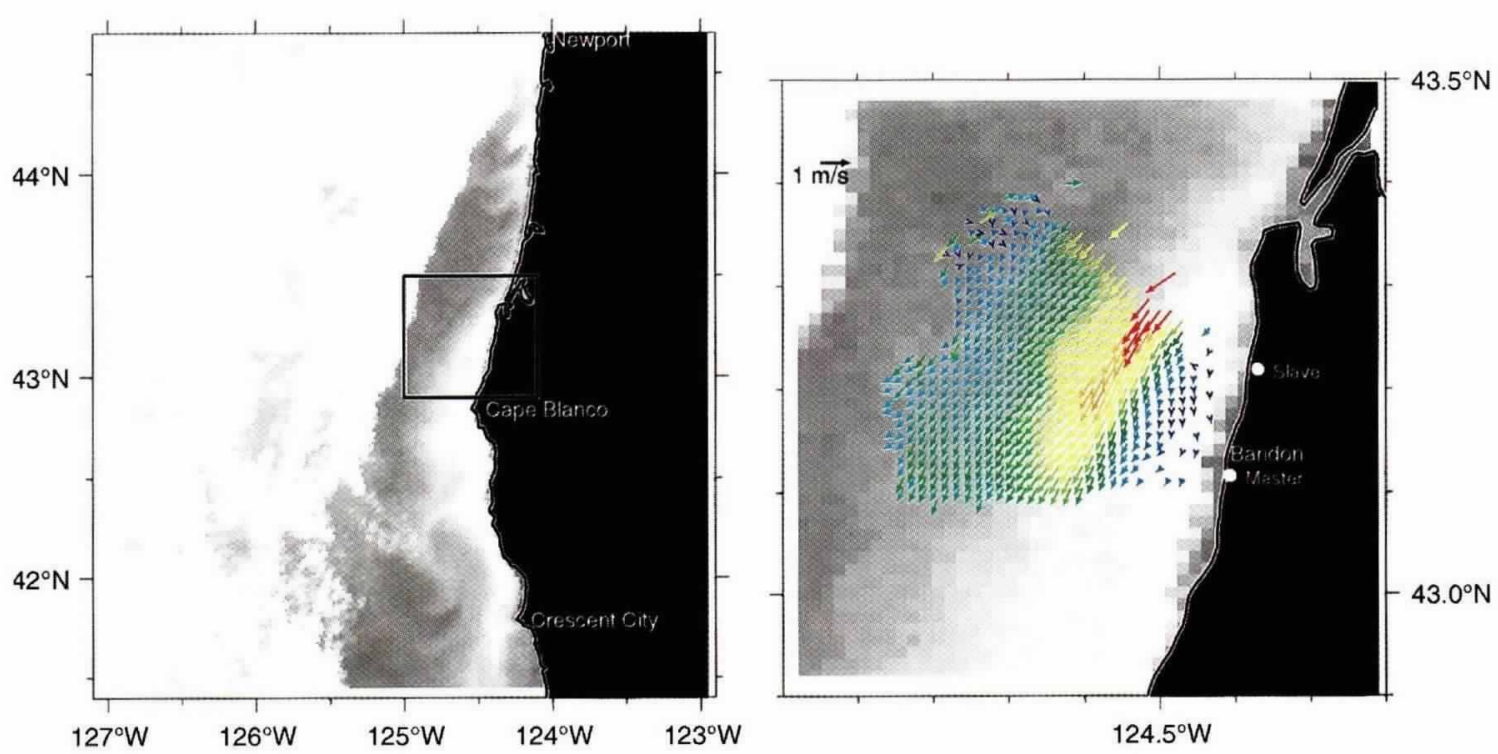

Fig. 3. Left: NOAA AVHRR image of sea surface temperature for 0200 UT on 18 May 1995. Light shades correspond to cold temperatures. Right: enlargement of boxed region from left panel, with tidal average of currents from the end of the deployment (0240 to 1500 UT on 17 May 1995). Current speeds are color coded from blue (lowest) to red (highest). 
ter (AVHRR) images of sea surface temperature is very intermittent due to clouds, but the first clear image following the southward acceleration (Fig. 3 ) is also the first image of spring 1995 to clearly show a band of cold water along the coast. Moreover, when the surface current field from the radar is overlaid on the satellite AVHRR image of sea surface temperature (Fig. 3), the identification of the strong radar currents with the coastal jet is clear. At this time, the core of the jet is directed along $210^{\circ} \mathrm{T}$, paralleling the front of cold, coastally upwelled water seen in the satellite image and the local isobaths north of $43.2^{\circ} \mathrm{N}$. The core speed of the jet decreases markedly over the sampling region, entering at $0.9 \mathrm{~m} \mathrm{~s}^{-1}$ in the northeast, centered just inshore of the $100-\mathrm{m}$ isobath, and slowing to $0.6 \mathrm{~m} \mathrm{~s}^{-1}$ as it exits the region $20 \mathrm{~km}$ to the southwest and offshore of the $100-\mathrm{m}$ isobath. The crossshore width of the jet, if defined by the region moving at least $0.5 \mathrm{~m} \mathrm{~s}^{-1}$, is $\sim 12 \mathrm{~km}$, narrowing slightly along the course of the jet.

The near-surface geostrophic flow, shown by the dynamic topography measured from $R / V W e$ coma during 17-19 May 1995 (Barth and Smith, 1997), confirms the presence of the coastal jet near midshelf, at the location indicated by the radar (Fig. 4). The spreading of the dynamic height contours below $43.2^{\circ} \mathrm{N}$ indicates a slowing

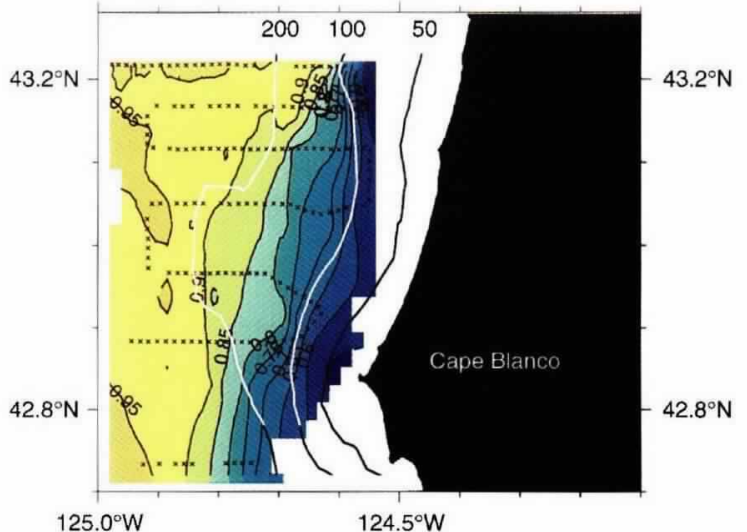

Fig. 4. Dynamic height $\Delta D 23 / 55\left(\mathrm{~m}^{2} \mathrm{~s}^{-2}\right)$ from SeaSoar survey conducted 17-19 May 1995. Dots show location of measurements.

of the current to the south, a feature also seen in the radar (Fig. 3). The dynamic height contours at the core of the jet are seen to cross the 100-m isobath, also as seen in the radar.

A more detailed look at the development of the coastal jet can be obtained from a time series of averaged radar maps (Fig. 5; here tidal averages have been made over maps covering $12 \mathrm{~h}$ and 20 min, starting at 0000 UT or 1200 UT). During 11
. . confirms the

presence of the

coastal jet near mid-

shelf, at the location

indicated by the

radar.
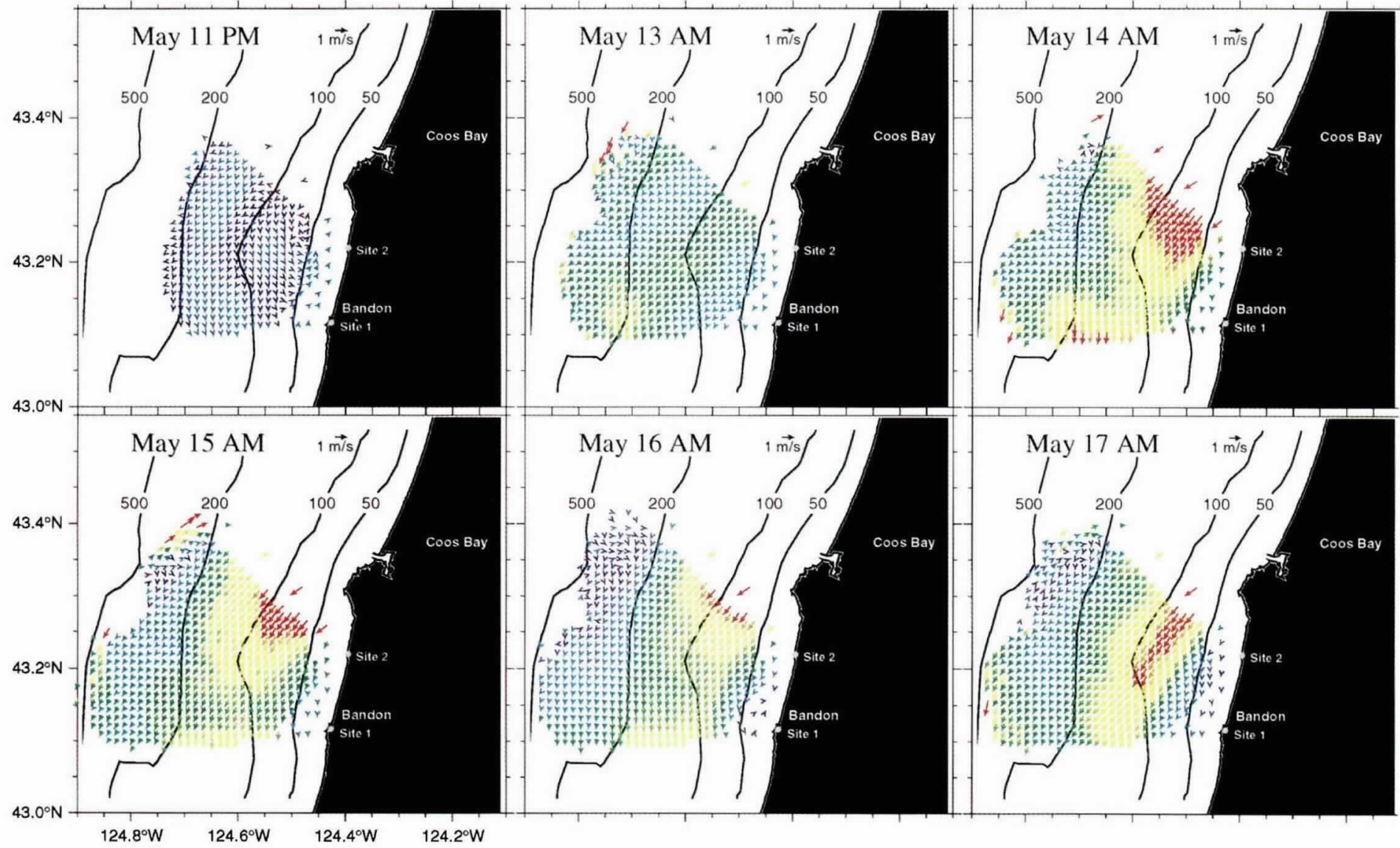

Fig. 5. Maps of surface currents from OSCR. Each map is an average over $12 \mathrm{~h}$ and 20 min, to minimize tidal effects. Current speeds are color coded from blue (lowest) to red (highest). 


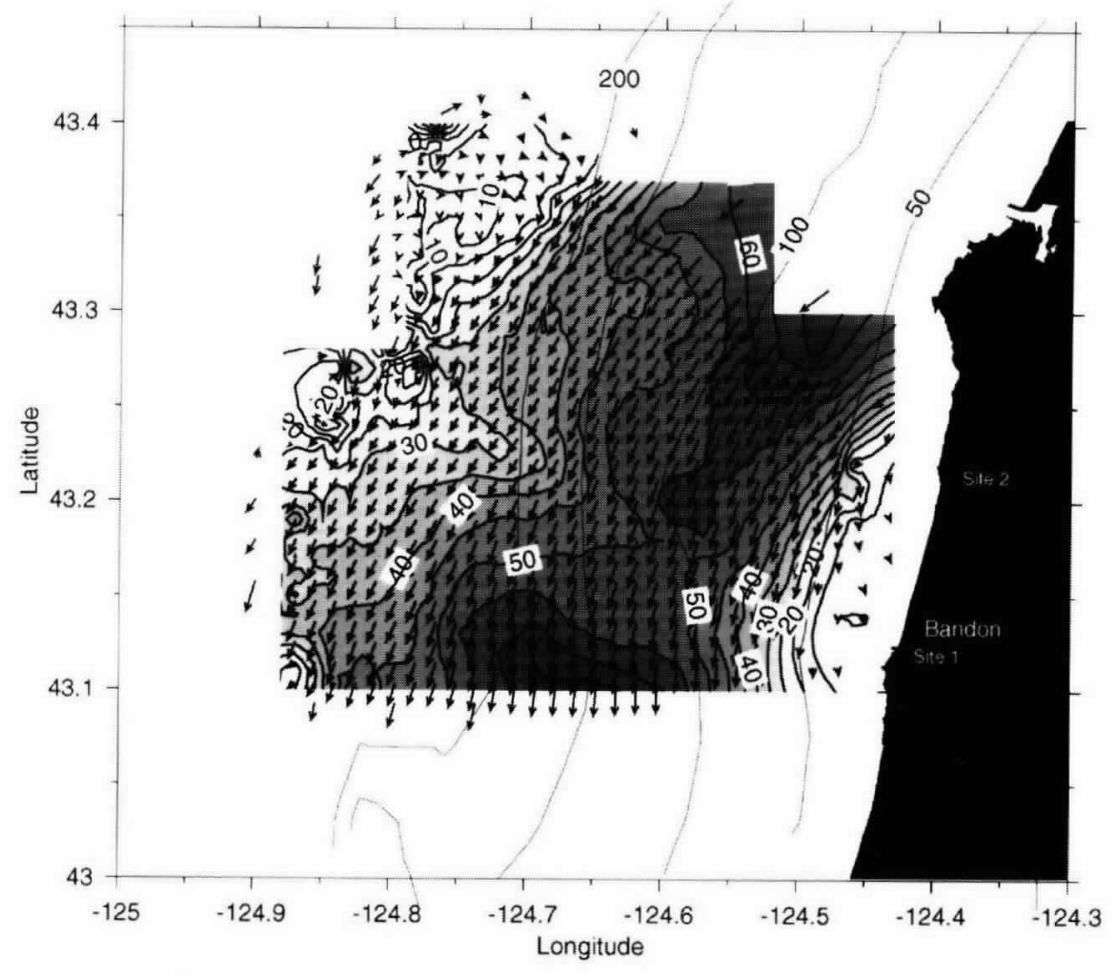

Fig. 6. Average current, 11-17 May 1995. Contours show speed of average current, in $\mathrm{cm} \mathrm{s}^{-1}$.

The strength and

persistence of the

spatial variability

measured over short

distances along the

current core is a sur-

prising result ... and 12 May, currents were quite weak (except for some outliers at long range that were not detected by automatic screening criteria). During 13-14 May, as the winds became strong and upwelling favorable (Fig. 2), the current field accelerated equatorward (Fig. 5), while during 15 and 16 May, in concert with weakening and even reversing winds, alongshore currents weakened, then reaccelerated on 17 May, again in response to the winds.

The mean radar currents (Fig. 6), as well as most of the twice-daily maps (Fig. 5) show a deceleration of the currents south of $43.2^{\circ} \mathrm{N}$, with a reacceleration of the currents at the very southern end of the radar coverage. The spatial variability along the current core is strong $[\mathrm{O}(20 \%)]$ and persistent, and is seen on scales similar to those of the topographic variability, although there is not a direct correspondence between water depth and current speed in this strongly baroclinic flow. Finally, there is a distinct tendency for the currents to be directed nearly southwestward at the inflow to the mapping region, but to be directed southward at the exit of the mapping region, following the tendency in the bathymetry; the rotation is $\sim 45^{\circ}$ in the overall mean current field along the 100 -m isobath.

\section{Summary}

The HF coastal radar provides a new look at the spatial and temporal variability in the coastal ocean off Oregon. Features observed in earlier studies, such as the formation of an alongshore coastal jet at midshelf in response to upwelling-favorable winds, and the steering of currents by topography, are observed clearly in these radar maps, now with very high resolution in time and in space. The strength and persistence of the spatial variability measured over short distances along the current core is a surprising result, as is the apparent tendency for the current jet to accelerate and decelerate in place. A longer time series of radar measurements, in conjunction with measurements in the water column from drifters, moored current meters, and rapid surveys, is needed to understand the detailed dynamics of this wind-driven variability.

\section{Acknowledgments}

We thank Duncan Ross, Ivy Iverson, and the GEC Marconi Corporation for providing and operating the OSCR during this demonstration; Lynda Shapiro and the staff of Oregon Institute of Marine Biology; Walt Waldorf and Joyce Federiuk; and the Oregon State Parks and Recreation Department. This research was funded by the Office of Naval Research (grant N000149511104), National Science Foundation (OCE 9512695 and 9314370), and Oregon State University.

\section{References}

Barth, J.A. and R.L. Smith, 1997: Separation of a coastal upwelling jet at Cape Blanco, Oregon, USA. S. Afr. J. Mar. Sci. In press.

Huyer, A., 1990: Shelf circulation. In: The Sea, Ocean Engineering Science, vol 9, B. Le Mehaute and D.M. Hanes, eds. Wiley, New York, 423-466.

B.M. Hickey, J.D. Smith, R.L. Smith and R.D. Pillsbury, 1975: Alongshore coherence at low frequencies in currents observed over the continental shelf off Oregon and Washington. J. Geophys. Res., 80(24), 3495-3505. , E.J.C. Sobey and R.L. Smith, 1979: The spring transition in currents over the Oregon continental shelf. $J$. Geophys. Res., 84(C11), 6995-7011.

Mooers, C.N.K., C.A. Collins and R.L. Smith, 1976: The dynamic structure of the frontal zone in the coastal upwelling region off Oregon. J. Phys. Oceanogr., 6, $3-21$.

Strub, P.T., J.S. Allen, A. Huyer and R.L. Smith, 1987: Largescale structure of the spring transition in the coastal ocean off western North America. J. Geophys. Res., 92 (C2), 1527-1544. $\square$ 